with the largest sources of fission products in Europe and will have by the end of this year a 5,000-curie cobalt and a 5,000-curie cæsium source. By the middle of next year these sources will be doubled, and mega-curie sources for irradiations will be available from fuel elements from a new reactor. It is planned to use for irradiations, machines such as linear accelerators to complement the irradiation programme. This new Group will investigate all possible uses for the millions of curies of fission products which will be available within a short time from British reactors. Already a number of promising applications are being investigated, such as the physical changes due to irradiation of a number of substances and especially those of plastics. Of great interest also is the sterilization of drugs and the possible extension of shelf-life due to radiation. Quite a number of chemical changes which are initiated by irradiation are being investigated already. This new Group will work closely with industrial concerns, and special arrangements are being made so that industry should profit to the fullest extent from this co-operation.

\section{Professional Civil Servants}

IN his speech at the opening of the tenth annual delegate Conference of the Institution of Professional Civil Servants on May 23, the general secretary, Mr. Stanley Mayne, quoted a recent statement by Dr. (now Sir) A. Fleck that in Britain we have only 64,000 scientists instead of the 90,000 we need. Mr. Mayne said that, in spite of repeated authoritative statements since the Barlow report on scientific man-power, made by the Advisory Council on Scientific Policy and others, there is no indication in the programme of either of the major political parties that it is realized that the supply of scientists and technologists is a major factor in national survival. Mr. Mayne referred also to the establishment in 1945 of the National Agricultural Advisory Service to ensure that the results of scientific research are brought immediately and directly before the industry by skilled interpreters, and he contrasted the prospects offered to the honours graduate entering on such a career with those open to the honours graduate in arts entering the administrative class of the Civil Service. He thinks that the Royal Commission on the Service should ensure that it is no less worth while taking up a scientific, professional or technical career in the Civil Service than it is to take up another type of careor. It is also essential to make science teaching an attractive career, as well as to increase the number of science teachers, while facilities for more science students are required both in the schools and the universities. Although something has been attempted in regard to science teachers, Mr. Mayne suggested it was too little and too late; nor does he agree with the University Grants Committee that no further sub. stantial increase in the number of university students can be expected in the immediate future without reducing university standards. We need a sharp improvement in educational facilities, he said, for the present extraordinary variation in educational opportunity in different parts of Britain represents lost opportunities of equipping the young people who, in a few years, will be running industries and conducting research. He thought that the Institution has a great responsibility for stimulating the more consistent and comprehensive thinking which is required about the minimum necessities for the economic survival, let alone the progress, of Britain.

\section{Cancer Chemotherapy National Committee in the United States}

In the belief that the state of knowledge of chemotherapy has advanced sufficiently to warrant a national voluntary co-operative programme of research and development for the treatment of cancer by drugs, a Cancer Chemotherapy National Committee has been formed in the United States, headed by Dr. Sidney Farber, scientific director of the Children's Cancer Research Foundation in Boston, with Dr. Kenneth M. Endicott, of the National Cancer Institute, Bethesda, Maryland, as the executive secretary. The sponsoring organizations are the American Cancer Society, the U.S. Atomic Energy Commission, the Damon Runyon Memorial Fund for Cancer Research, the Food and Drug Administration, the National Cancer Institute of the U.S. Department of Health, Education and Welfare, and the Veterans Administration. Representatives of these organizations met recently at the National Institutes of Health, Bethesda, to form the National Committee, and they also appointed an advisory group of six for liaison with the pharmaceutical and chemical industries. In addition, four technical advisory panels have been established and are meeting to assess the progress in cancer chemotherapy research and make recommendations for the future. These panels will cover the fields of chemistry, pharmacology, screening of chemical compounds through experiments on animals, and clinical studies. The sponsoring agencies are providing a small fulltime staff, headed by Dr. Endicott, to administer the programme, organize an information exchange and give needed assistance to research scientists. The Committee, which including Dr. Farber consists of ten, will define the scope of the programme, develop general policies, assist in obtaining financial support for the work, co-ordinate the activities of the sponsoring organizations, and observe the rate of progress of the entire effort.

\section{The Coffee Pot: a New Club in London for Young Professional Workers}

MANY young men and women commencing pro. fessional jobs far from the towns in which their parents live find it difficult to meet others who share their interests. To meet the needs of such people, a new club has been opened in London-The Coffee Pot-directed by a committee composed largely of recent graduates and three or four senior members. The club is intended for younger members of the professions, particularly those who are not natives of London. Membership is open to men and women between the ages of nineteen and thirty. The subscription is $£ 2$ a year, and there is no entrance fee. There is an 'at home' at the Coffee Pot Club every Monday during 7.30-10 p.m., and there are restaurant and club lounge facilities on Mondays, Tuesdays, Thursdays and Fridays. It is hoped to open other such clubs in various towns, and there are schemes for a London Coffee Pot which will be open every day. Further information can be obtained from the Secretary, The Coffee Pot, 83 Chiltern St., London, W.1.

\section{Origin of the $n$-Sound in Speech}

Is his paper "Some Remarks on the Origin of the n-Sound" (Reykjavík, 1954), Prof. Alexander Jóhannesson, of the University of Iceland, expands, with special reference to the $n$-sound, the theory which, in these pages and elsewhere (see Nature, 166, 